\title{
An Open-label, Phase II Study of the Safety and Tolerability of Pirfenidone in Patients with Scleroderma-associated Interstitial Lung Disease: the LOTUSS Trial
}

\author{
Dinesh Khanna, Carlo Albera, Aryeh Fischer, Nader Khalidi, Ganesh Raghu, Lorinda Chung, \\ Dan Chen, Elena Schiopu, Margit Tagliaferri, James R. Seibold, and Eduard Gorina
}

\begin{abstract}
Objective. Systemic sclerosis-associated interstitial lung disease (SSc-ILD) shares a number of clinical features and pathogenic mechanisms with idiopathic pulmonary fibrosis (IPF). This study was designed to evaluate the tolerability of the IPF treatment pirfenidone in SSc-ILD. The known gastrointestinal, skin, and liver adverse events (AE) of pirfenidone are of importance given the involvement of these organs in SSc.

Methods. All patients received pirfenidone and were randomized 1:1 to either a 2- or 4-week titration starting at $801 \mathrm{mg} /$ day and finishing at a maintenance dose of $2403 \mathrm{mg} /$ day. Patients received pirfenidone for 16 weeks in total. Assessments included treatment-emergent AE (TEAE) and exploratory disease outcomes.

Results. Sixty-three patients were randomized; $96.8 \%$ experienced a TEAE and more patients reported TEAE during the titration versus the maintenance period. The most commonly reported TEAE were consistent with those observed for pirfenidone in IPF (nausea, headache, fatigue) and were similar regardless of titration schedule. More patients discontinued treatment because of TEAE in the 2 - versus 4-week titration group ( 5 vs 1 , respectively); all discontinuation events occurred $>3$ weeks after reaching the full dose of pirfenidone. Mycophenolate mofetil (MMF), taken by $63.5 \%$ of patients in addition to pirfenidone, did not appear to affect tolerability. Exploratory disease outcomes remained largely unchanged.

Conclusion. Pirfenidone showed an acceptable tolerability profile in SSc-ILD, although a longer titration may be associated with better tolerability. Tolerability was not affected by concomitant MMF. The present findings support further investigation of pirfenidone in future clinical trials in patients with SSc-ILD. Trial registration: ClinicalTrials.gov; www.clinicaltrials.gov NCT01933334. (First Release July 1 2016; J Rheumatol 2016;43:1672-9; doi:10.3899/jrheum.151322)
\end{abstract}

Key Indexing Terms: SYSTEMIC SCLEROSIS

SCLERODERMA SAFETY

\section{INTERSTITIAL LUNG DISEASES} TOLERABILITY
Interstitial lung disease (ILD) is a frequent complication of systemic sclerosis (SSc), a rare heterogeneous systemic autoimmune disease, characterized by excessive collagen production and tissue fibrosis of the skin and internal organs $^{1,2}$. Up to $90 \%$ of patients with SSc show evidence of
ILD on high-resolution computed tomography (HRCT) and $40 \%-75 \%$ show impairment in pulmonary function tests ${ }^{2}$. Further, ILD and pulmonary arterial hypertension (PAH) are the 2 main causes of death in $\mathrm{SSc}^{2,3}$. SSc-ILD is characterized by interstitial and alveolar inflammation and fibrosis,
From the University of Michigan, Ann Arbor, Michigan; University of Colorado, Denver, Colorado; University of Washington, Seattle, Washington; Stanford University School of Medicine; Jazz Pharmaceuticals, Palo Alto; InterMune Inc., Brisbane, California; Scleroderma Research Consultants LLC, Litchfield, Connecticut, USA, University of Turin, Turin, Italy; McMaster University, Hamilton, Ontario, Canada.

Supported by InterMune Inc., which became a wholly owned subsidiary of F. Hoffmann-La Roche Ltd. in 2014. C.A. has received consulting fees from InterMune. E.S. has received a grant from InterMune to conduct this study. D.C., M.T., and E.G. were employees of InterMune at the time this study was conducted. J.R.S. has received consulting fees from InterMune.

D. Khanna, $M D, M S$, University of Michigan; C. Albera, MD, University of Turin; A. Fischer, MD, University of Colorado; N. Khalidi, MD,

FRCPC, McMaster University; G. Raghu, MD, University of Washington;
L. Chung, MD, Stanford University School of Medicine; D. Chen, MD PhD, Jazz Pharmaceuticals, and formerly of InterMune; E. Schiopu, MD, University of Michigan; M. Tagliaferri, MD, formerly of InterMune; J.R. Seibold, MD, Scleroderma Research Consultants LLC; E. Gorina, $M D, M S$, formerly of InterMune.

Dr. Seibold and Dr. Gorina are joint senior authors.

Address correspondence to Dr. D. Khanna, Professor of Medicine, Director, University of Michigan Scleroderma Program, Division of Rheumatology and Department of Internal Medicine, 300 North Ingalls St., SPC 5422, Ann Arbor, Michigan 48109, USA.

E-mail:khannad@med.umich.edu

Full Release Article. For details see Reprints/Permissions at jrheum.org. Accepted for publication May 27, 2016. 
typically manifesting on radiographic imaging and histology as a nonspecific interstitial pneumonia pattern ${ }^{4,5,6}$.

To date, there are no approved treatments for SSc-ILD. Treatment with cyclophosphamide (CYC) has been recommended $^{7}$; however, improvements in lung function are generally modest ${ }^{8,9}$ and concerns exist regarding its safety profile $^{2,7,10}$. Mycophenolate mofetil (MMF) is frequently used with the intention to stabilize lung function in SSc-ILD ${ }^{2,10,11}$, particularly in patients who cannot tolerate CYC. A study comparing MMF and CYC in patients with $\mathrm{SSc}$ is currently under way, with interim results showing a similar but minimal improvement for both treatments of about $4 \%-4.5 \%$ in percent-predicted forced vital capacity (FVC) at 24 months (Scleroderma Lung Study II, NCT00883129) 2,10,12.

Pirfenidone is an antifibrotic agent ${ }^{13}$ with antiinflammatory properties, including inhibition of proinflammatory cytokines ${ }^{14}$ and inhibition of inflammatory cell proliferation ${ }^{15}$. Pirfenidone was approved by European and US regulatory agencies in 2011 and 2014, respectively, for the treatment of patients with idiopathic pulmonary fibrosis (IPF) ${ }^{16,17,18,19}$, a chronic, progressive, and almost invariably fatal disease ${ }^{20}$. Unlike SSc-ILD, however, IPF is limited to the lungs and is defined by a pattern of usual interstitial pneumonia ${ }^{5}$. Despite differences in their clinical presentation $^{5}$, IPF and SSc-ILD share some overlapping pathogenic mechanisms, including injury to structural cells, fibroblast activation, myofibroblast accumulation, expression of fibrogenic cytokines and growth factors, and progressive ILD ${ }^{2,5,21}$.

Pirfenidone is generally well tolerated in patients with IPF, and compared with placebo, pirfenidone significantly reduces disease progression (as measured by change in percent-predicted FVC) and increases progression-free survival ${ }^{17,18,22}$. Pirfenidone also significantly reduces the risk of mortality in patients with IPF compared with placebo and can benefit patient outcomes including the 6-min walking distance and dyspnea ${ }^{17,23}$. However, pirfenidone is known to be associated with adverse events (AE) of the liver, gastrointestinal (GI) system, and $\operatorname{skin}^{17,18}$, which may overlap with the organ systems frequently affected in patients with $\mathrm{SSc}^{1,24,25}$. Therefore, in the setting of SSc-ILD, it is important to investigate the tolerability of pirfenidone before assessing its efficacy.

The LOTUSS study (An Open Label, RandOmized, Phase 2 STUdy of the Safety and Tolerability of Pirfenidone when Administered to Patients with Systemic Sclerosis-Related Interstitial Lung Disease) was designed to assess the safety and tolerability of pirfenidone in patients with SSc-ILD at the same therapeutic dose used in IPF, and using 2 dose-titration schedules, with or without stable background SSc-ILD therapy.

\section{MATERIALS AND METHODS}

Design and patients. The LOTUSS study (NCT01933334) was an international, multicenter, randomized, open-label, phase II study (Figure 1).
Eligible patients were men or women aged 18-75 years with a confirmed diagnosis of SSc based on the preliminary criteria of the American College of Rheumatology for the classification of $\mathrm{SSc}^{26}$ and an HRCT scan with evidence of ILD within 2 years of the study start. Eligibility criteria included SSc disease duration of $<7$ years from first non-Raynaud symptoms; percent-predicted FVC of $\geq 50 \%$; DLCO of $\geq 40 \%$ (adjusted for hemoglobin); absence of clinically significant PAH, right atrial or ventricular enlargement or left ventricular dysfunction; absence of underlying liver disease; and absence of moderate to severe gastroesophageal reflux [as assessed by the University of California Los Angeles Scleroderma Clinical Trial Consortium Gastrointestinal Tract (UCLA SCTC GIT) 2.0 questionnaire reflux subscale score $>1.0]^{27}$. Concomitant background SSc-ILD medication of oral CYC ( $\leq 2 \mathrm{mg} / \mathrm{kg} /$ day) or MMF ( $\leq 1.5 \mathrm{~g}$ twice daily) was permitted if patients had received a stable dose for $\geq 3$ months prior to study start. Full inclusion and exclusion criteria are provided in the Supplementary Material 1 (available online at jrheum.org).

We conducted our study in accordance with the International Conference on Harmonisation guidelines, consistent with the Declaration of Helsinki, and applicable laws and regulations of the countries in which the research was conducted. Local institutional review boards and independent ethics committees approved the protocol (Supplementary Table 1, available online at jrheum.org). All patients provided written informed consent.

Randomization. Patients received pirfenidone (267 mg oral capsules with food) at a starting dose of $801 \mathrm{mg} /$ day ( 1 capsule, $3 \times$ daily) titrated to a maintenance dose of $2403 \mathrm{mg} /$ day ( 3 capsules, $3 \times$ daily). Patients were randomized 1:1 to a 2-week titration group (as standard for patients with IPF) or a 4-week titration group (Figure 1). Randomization occurred through a blocked scheme prospectively prepared by the study sponsor and was stratified by background SSc-ILD treatment.

Assessments. Safety assessments were treatment-emergent AE (TEAE) and treatment-emergent serious $\mathrm{AE}$ (TE SAE), and their relationship to pirfenidone. AE were collected from study start until 28 days after the last dose or the posttreatment visit, whichever occurred later. Changes in clinical laboratory variables or electrocardiogram results were recorded. The frequency of GI symptoms and their effect on patient quality of life were assessed using the UCLA SCTC GIT 2.0 questionnaire $^{27}$.

Exploratory disease outcomes included relevant lung function assessments [percent-predicted FVC, DLCO (adjusted for hemoglobin)], patient-reported outcomes [Mahler baseline and Transition Dyspnea Indices (TDI), Health Assessment Questionnaire-Disability Index (HAQ-DI), patient's global assessment of disease activity (PtGA)], and the modified Rodnan skin score (mRSS).

Statistical analyses. The study was designed to enroll about 50 patients (25 per titration group) to provide $a \geq 95 \%$ probability of observing a common $\mathrm{AE}$ with a true event rate of $\geq 6 \%$. Analyses were summarized descriptively by titration group for all patients, for the entire treatment period, during the titration period (weeks 1-6) and during the maintenance period (weeks 7-16). Study endpoints were also summarized by subgroups, defined by background SSc-ILD treatment and type of cutaneous SSc. Fisher's exact test was used to provide $\mathrm{p}$ values for safety outcomes with numeric differences for descriptive purposes.

\section{RESULTS}

Patients. Overall, 63 patients were recruited at 18 sites across 3 countries (Canada, Italy, and the United States) and were randomized to the 2-week or 4-week pirfenidone titration groups (Figure 2). An additional 26 patients did not satisfy the eligibility criteria and were not randomized. The first patient was enrolled on October 31,2013, and the last patient completed the study on September 16, 2014. All randomized patients received $\geq 1$ dose of study medication.

Baseline demographics and clinical characteristics were

Personal non-commercial use only. The Journal of Rheumatology Copyright (c) 2016. All rights reserved. 


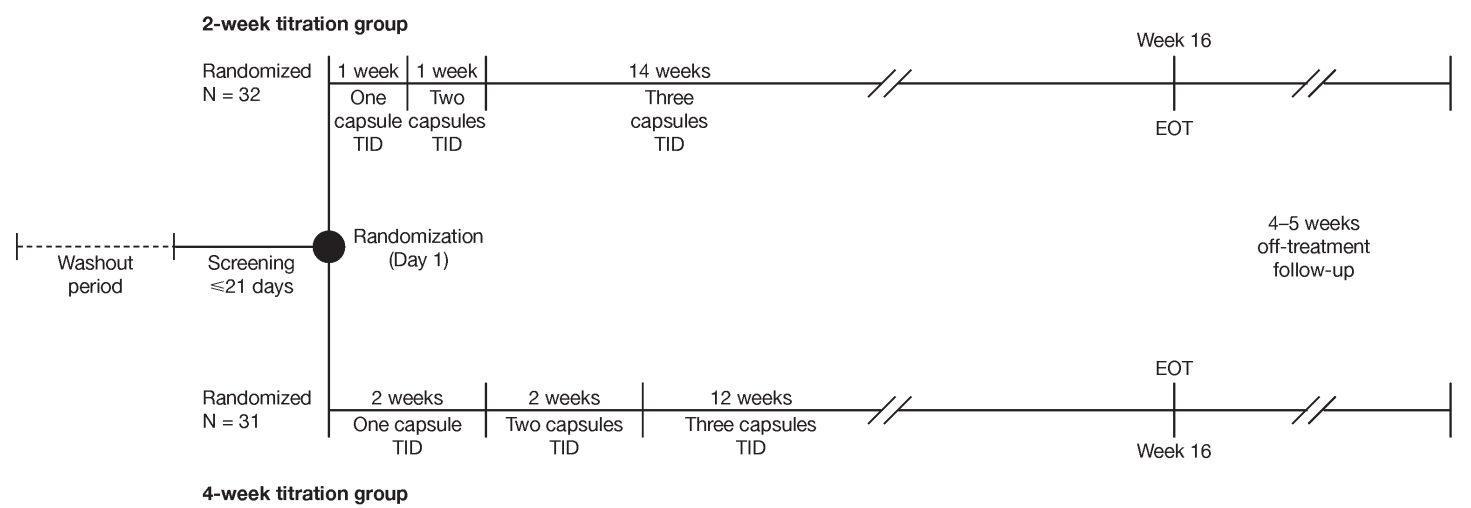

Figure 1. LOTUSS study design. Analysis periods were defined as follows: titration period, weeks 1-6; maintenance period, weeks 7-16. LOTUSS: An Open Label, RandOmized, Phase 2 STUdy of the Safety and Tolerability of Pirfenidone when Administered to Patients with Systemic Sclerosis-Related Interstitial Lung Disease; TID: $3 \times$ daily; EOT: end of treatment.

Table 1. Summary of baseline demographic characteristics. Values are $\mathrm{n}(\%)$ unless otherwise specified.

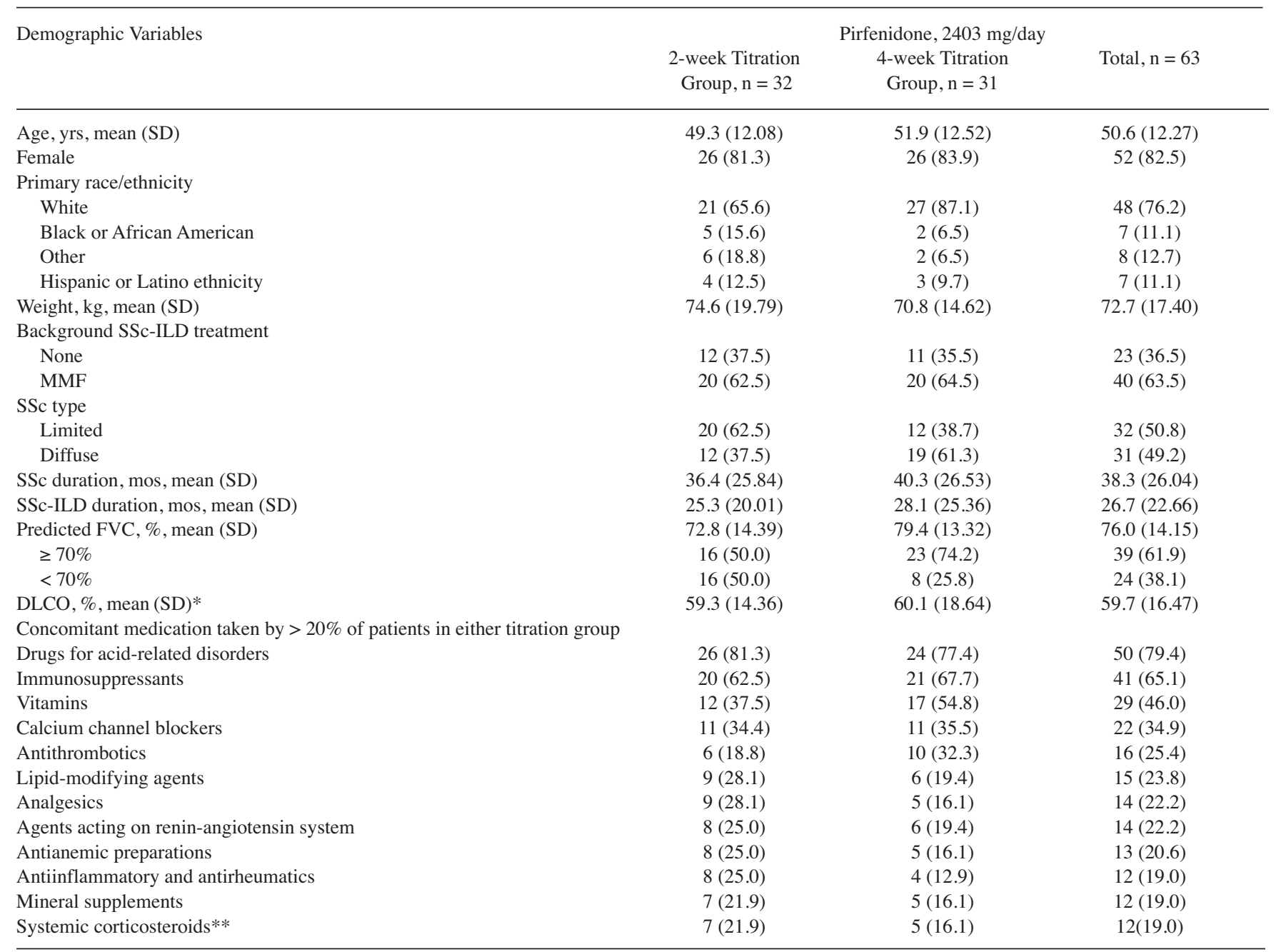

*Adjusted for hemoglobin. ** Oral corticosteroids for systemic use were permitted at a dose $\leq 10 \mathrm{mg} /$ day prednisone equivalent. SSc: systemic sclerosis; ILD: interstitial lung disease; MMF: mycophenolate mofetil; FVC: forced vital capacity. 


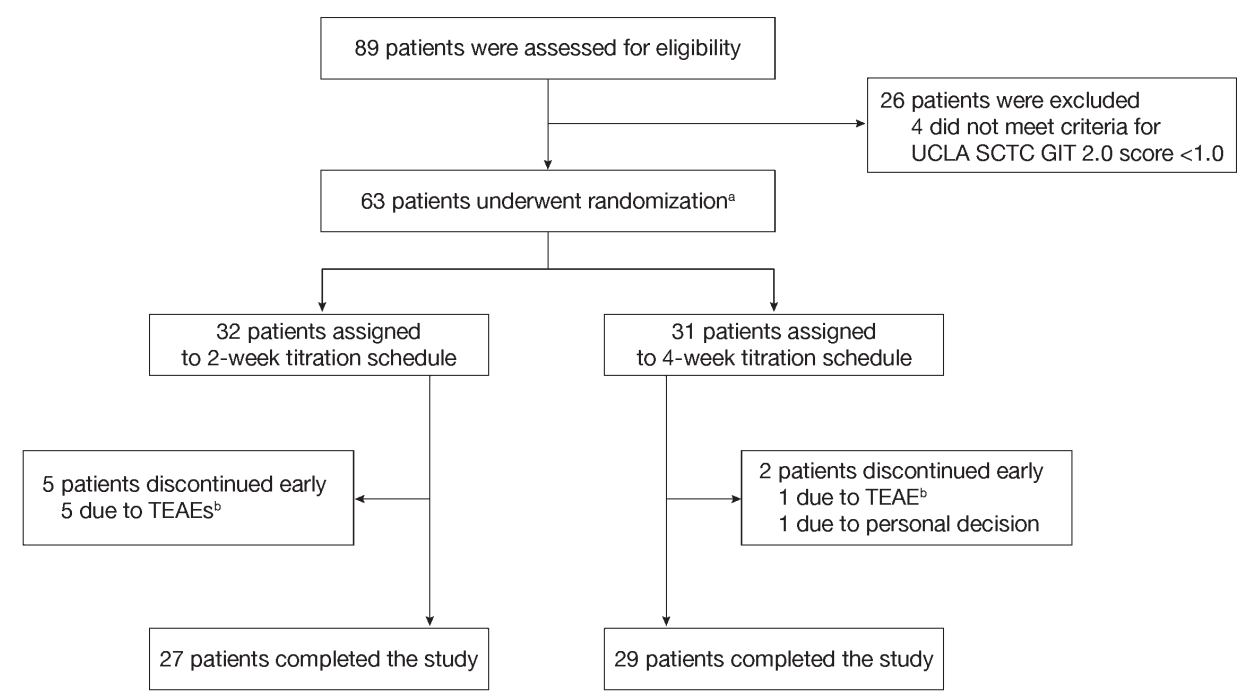

Figure 2. Summary of patient disposition. ${ }^{\text {a }}$ Following initiation of study medication, 3 patients were discovered to not meet all eligibility criteria [DLCO $<40 \%(\mathrm{n}=2)$ and systemic sclerosis disease duration $>7 \mathrm{yrs}(\mathrm{n}=1)$ ], but were permitted to continue. ${ }^{\mathrm{b}}$ All TEAE leading to discontinuation started $>3$ weeks after completion of the 2- or 4-week titration. TEAE: treatment-emergent adverse event; UCLA SCTC GIT: University of California Los Angeles Scleroderma Clinical Trial Consortium Gastrointestinal Tract.

comparable in the 2 titration groups with the exception that more patients in the 2-week titration group had limited SSc and that the 4-week titration group had slightly better lung function (Table 1). Background SSc-ILD medication was used by $63.5 \%$ of patients, all of whom were receiving MMF (Table 1). No patients were receiving CYC. Prednisone was used by $17.5 \%$ of patients.

Most patients (88.9\%) completed our study; 7 patients (11.1\%) withdrew early, 6 (9.5\%) because of AE (5 in the 2 -week group and 1 in the 4-week group; Figure 2). All patients reached the target dose of pirfenidone $2403 \mathrm{mg}$ /day, except 1 patient in the 2 -week group owing to a site dosing error.

Overall, $57.1 \%$ of patients had a dose adjustment; in both titration groups, the majority of dose adjustments occurred during the maintenance versus titration period (dose reductions: $48.4 \%$ vs $12.7 \%$, respectively; dose interruptions: $22.6 \%$ vs $6.3 \%$, respectively). Patients in the 2 -week titration group had more dose adjustments overall compared with the 4-week group; the difference between the 2 titration groups was most striking during the titration period (dose reductions: $21.9 \%$ vs $3.2 \%$, difference $18.7 \%, \mathrm{p}=0.0534$; dose interruptions: $12.5 \%$ vs $0 \%$, difference $12.5 \%, \mathrm{p}=0.1132$, for the 2- vs 4-week group, respectively).

Safety. Overall, $96.8 \%$ of patients experienced at least 1 TEAE (Table 2A). The most commonly reported TEAE were nausea, headache, and fatigue. The frequency and type of TEAE were similar for both the 2- and 4-week titration groups (Table 2A).

A greater proportion of patients experienced TEAE during the titration versus the maintenance period $(92.1 \%$ vs $79.0 \%)$.
Of the TEAE reported by $>10 \%$ of patients during the entire treatment period (Table 2B), nausea (44.4\% vs $8.1 \%$ ), gastroesophageal reflux disease (19.0\% vs $4.8 \%)$, fatigue (31.7\% vs $9.7 \%$ ), and headache (30.2\% vs $19.4 \%)$ were reported in more patients during the titration versus the maintenance period. Rash was reported in more patients during the maintenance period (17.7\% vs $4.8 \%$ during the titration period).

The majority of TEAE were mild or moderate in intensity ${ }^{28}$. Sixteen severe TEAE were reported by 12 patients, $9(28.1 \%)$ and $3(9.7 \%)$ of whom were in the 2 - and 4-week titration groups, respectively (difference $18.4 \%, \mathrm{p}=$ 0.1069; Table 2A). Overall, most severe TEAE were reported after the completion of the titration periods (13/16 TEAE) and when the patients had been receiving the full dose of pirfenidone for $>2$ weeks (11/16 TEAE). Severe TEAE reported by $>1$ patient were fatigue (4.8\%), diarrhea (3.2\%), and nausea (3.2\%; Table 2B).

Three patients reported 4 TE SAE; all events were new in onset and occurred in the 2-week titration group during the maintenance period. TE SAE were bronchitis (not related to study medication, per site investigator), intestinal obstruction (possibly related to study medication), and PAH (associated with SSc and diagnosed by right heart catheterization) alongside worsening ILD (neither of which were related to the study medication). The patient with PAH/ILD also discontinued the study because of PAH. A further 5 patients discontinued the study (Table 2A): 3 because of skin-related TEAE ( 2 in the 2-week group and 1 in the 4-week group); 1 patient owing to drug hypersensitivity to pirfenidone (with vomiting, 2-week group); and 1 patient after an exacerbation

Personal non-commercial use only. The Journal of Rheumatology Copyright @ 2016 . All rights reserved. 
Table 2A. Summary of TEAE. Values are $\mathrm{n}(\%)$.

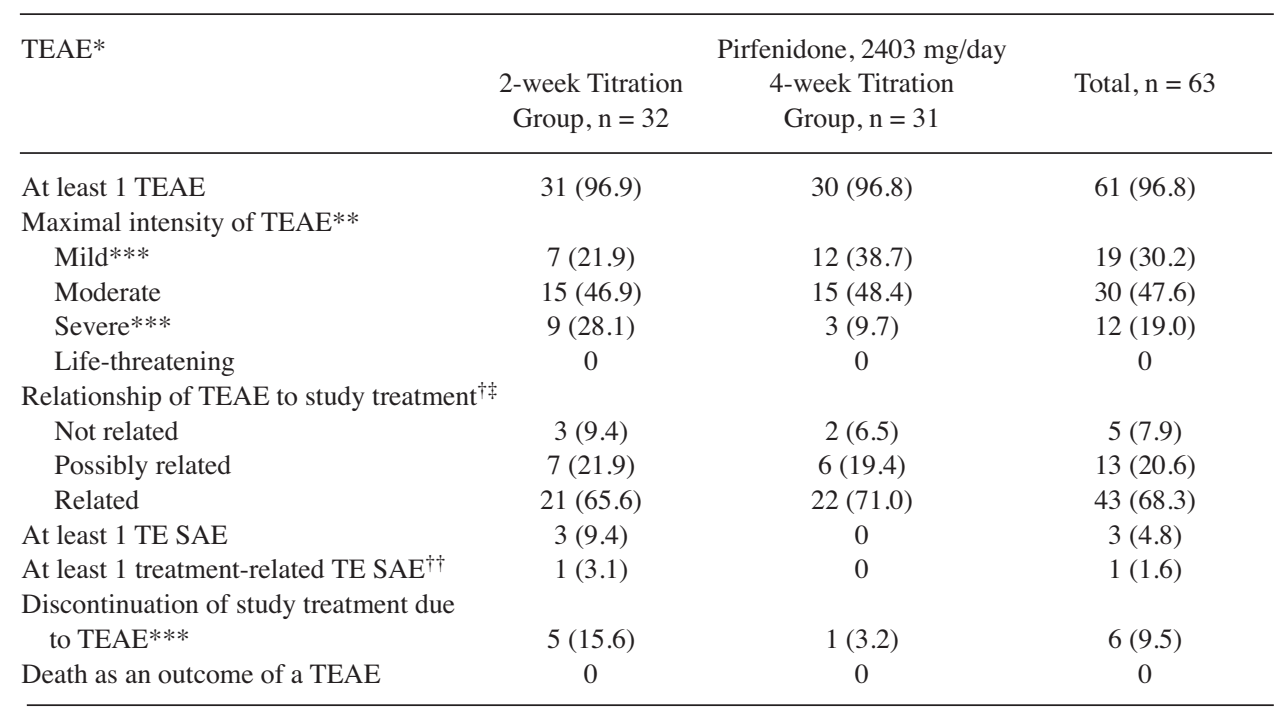

* AE were classified according to Medical Dictionary for Regulatory Activities, version 11.0, using preferred terms within each system organ class, and the severity of AE was recorded according to the Common Terminology Criteria for $\mathrm{AE}$, version $4.0^{28}$. ** Each patient was counted only once as the maximal intensity of any event for that patient. *** Events with treatment differences $\geq 10 \%$; p values by the Fisher's exact test all $>0.1 .{ }^{\dagger}$ Each patient was counted only once as the strongest relationship of any event for that patient. $\ddagger$ As assigned by the investigator. ${ }^{\dagger} \mathrm{An} \mathrm{AE}$ was considered serious if it resulted in death, required hospitalization, resulted in persistent or significant disability, resulted in a congenital anomaly or birth defect, or was an important medical effect, defined as an event that may have jeopardized the patient and may have required intervention to prevent death, an immediate threat to life, or hospitalization. AE: adverse event; TEAE: treatment-emergent AE; TE SAE: treatment-emergent serious AE.

of existing fibromyalgia (2-week group). All TEAE leading to discontinuation occurred $>3$ weeks after reaching the full dose of pirfenidone. No life-threatening TEAE or deaths occurred.

The incidence of TEAE was generally comparable in the predefined subgroups. However, the incidence of infections was higher in the no-MMF versus MMF subgroup ( $\mathrm{n}=13$, $56.5 \%$ vs $\mathrm{n}=10,25.0 \%$, respectively, difference $31.5 \%, \mathrm{p}=$ $0.0161)$. A greater proportion of patients reported severe TEAE in the no-MMF versus MMF subgroup $(\mathrm{n}=8,34.8 \%$ vs $\mathrm{n}=4,10.0 \%$, respectively, difference $24.8 \%, \mathrm{p}=0.0223$ ) and in the diffuse versus limited cutaneous SSc subgroup (n $=8,25.8 \%$ vs $\mathrm{n}=4,12.5 \%$, respectively, difference $13.3 \%$, $\mathrm{p}=0.2132$ ). Similarly, more patients discontinued treatment because of a TEAE in the no-MMF versus MMF subgroup $(\mathrm{n}=4,17.4 \%$ vs $\mathrm{n}=2,5.0 \%$, respectively, difference $12.4 \%$, $\mathrm{p}=0.1794)$, as did patients with diffuse versus limited cutaneous SSc $(\mathrm{n}=5,16.1 \%$ vs $\mathrm{n}=1,3.1 \%$, respectively, difference $13.0 \%, \mathrm{p}=0.1042)$.

Results for the patient assessment of GI symptoms using the UCLA SCTC GIT 2.0 questionnaire at Day 1 and Week 16 showed that mean total GIT scores and subscale scores remained stable throughout the study with no notable differences between the 2- and 4-week titration groups (Supplementary Table 2, available online at jrheum.org). Liver function tests showed that bilirubin values did not exceed the upper limit of normal (ULN) and aminotransferase levels remained below $3 \times$ the ULN. Minor elevations in liver function tests were sporadic and not considered clinically relevant. There were no abnormalities identified in other clinical laboratory data.

Exploratory disease outcomes. Percent-predicted FVC and DLCO values were basically unchanged throughout our study, and no clinically relevant differences were observed in lung function variables between the 2- and 4-week groups or in any of the subgroup analyses (Table 3). Mean change from baseline in percent-predicted FVC was $0.6 \%$ and $-0.3 \%$ in the MMF and no-MMF subgroups at Week 16, respectively; mean change from baseline in percent-predicted DLCO was $3.2 \%$ and $-0.2 \%$ in the MMF and no-MMF subgroups at Week 16, respectively (Table 3 ).

Relative to baseline at Week 16, dyspnea remained unchanged with a mean score of 1.0 on the Mahler TDI scale in all patients. Mean change from baseline in Mahler overall TDI score was greater in the 4- versus 2-week titration group (Table 3) and dyspnea was slightly more pronounced at baseline and more improved at Week 16 in the MMF versus no-MMF subgroup (Table 3).

Skin thickening, as measured by mean mRSS total score, remained unchanged from baseline to Week 16 (Table 3) and no clinically relevant differences were seen at Week 16 in the 2 - versus 4 -week titration groups or in the subgroup analyses.

Personal non-commercial use only. The Journal of Rheumatology Copyright $\subset$ $\subset$ 2016. All rights reserved 
Table $2 B$. TEAE reported in $\geq 10 \%$ of patients from both treatment groups overall. Values are $\mathrm{n}(\%)$.

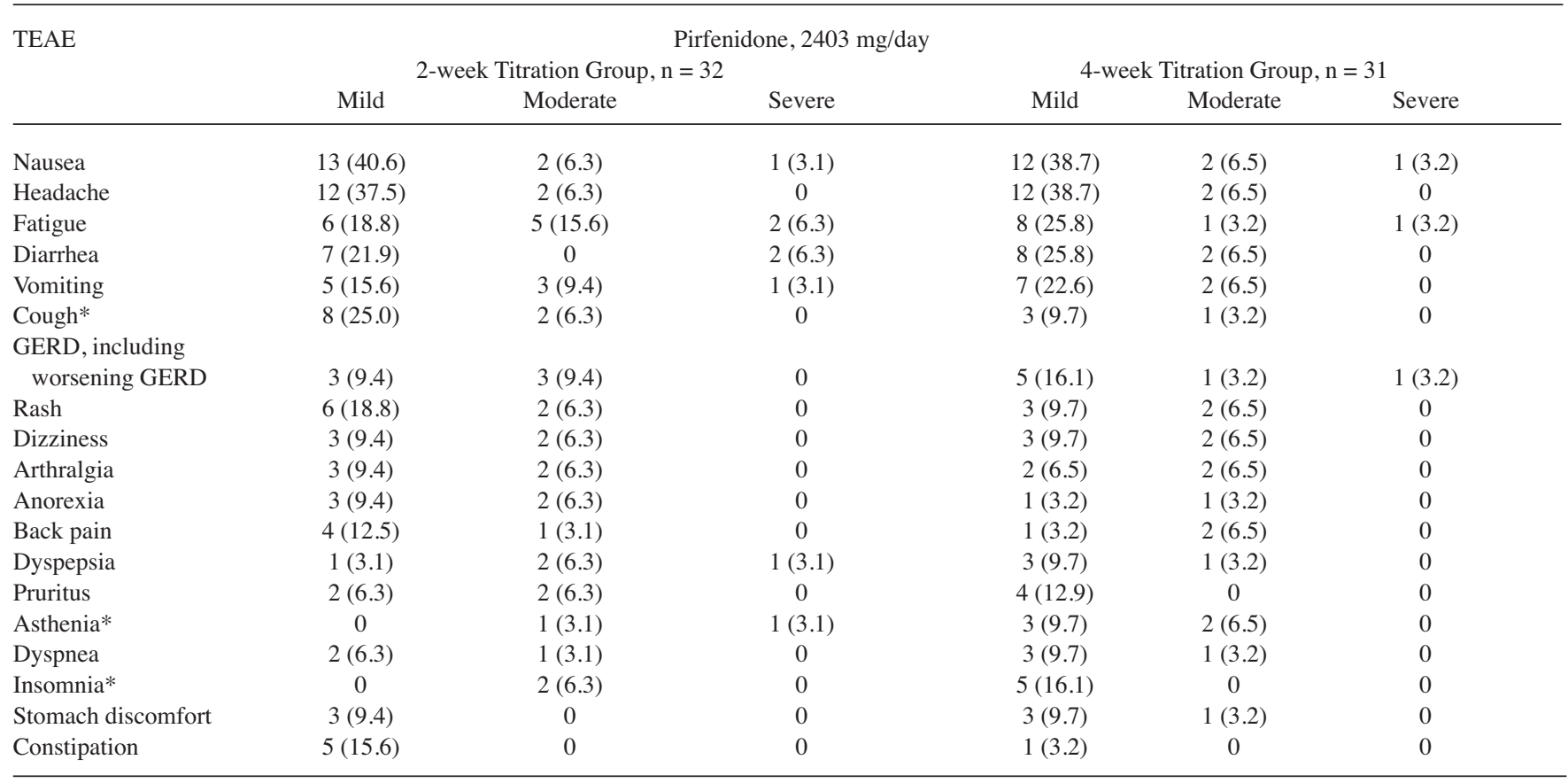

* Events with treatment differences $\geq 10 \%$; $\mathrm{p}$ values by the Fisher's exact test all $>0.1$. TEAE: treatment-emergent adverse event; GERD: gastroesophageal reflux disease.

Table 3. Summary of exploratory disease outcomes.

\begin{tabular}{|c|c|c|c|c|c|}
\hline \multirow[t]{2}{*}{ Variables } & \multicolumn{5}{|c|}{ Pirfenidone, $2403 \mathrm{mg} /$ day } \\
\hline & $\begin{array}{l}\text { 2-week Titration } \\
\text { Group, } \mathrm{n}=32\end{array}$ & $\begin{array}{l}\text { 4-week Titration } \\
\text { Group, } \mathrm{n}=31\end{array}$ & No MMF, $\mathrm{n}=23$ & $\mathrm{MMF}, \mathrm{n}=40$ & Total, $\mathrm{n}=63$ \\
\hline \multicolumn{6}{|l|}{ Predicted FVC, \%, mean (SD) } \\
\hline Baseline & $72.8(14.39)$ & $79.4(13.32)$ & $78.7(13.99)$ & $74.5(14.19)$ & $76.0(14.15)$ \\
\hline Week 16 & $71.4(15.14)$ & $78.7(13.60)$ & $75.5(14.26)$ & $75.0(15.13)$ & $75.2(14.71)$ \\
\hline Change from baseline to Week $16^{*}$ & $-0.6(8.91)^{*}$ & $-0.6(5.90)$ & $-0.3(9.50)^{* *}$ & $0.6(5.82)^{* * *}$ & $-0.6(7.44)^{*}$ \\
\hline \multicolumn{6}{|l|}{ Predicted DLCO, $\%$, mean $(\mathrm{SD})^{\dagger}$} \\
\hline Baseline & $59.3(14.36)$ & $60.1(18.64)$ & $56.8(14.92)$ & $61.4(17.26)$ & $59.7(16.47)$ \\
\hline Week 16 & $60.6(19.12)^{*}$ & $63.4(18.12)$ & $57.0(14.96)^{* *}$ & $64.7(19.80)^{* * *}$ & $62.0(18.51)$ \\
\hline Change from baseline to Week $16^{*}$ & $0.7(9.57)^{*}$ & $3.2(10.00)$ & $-0.2(7.12)^{* *}$ & $3.2(10.85)^{* * *}$ & $2.0(9.79)^{*}$ \\
\hline \multicolumn{6}{|l|}{ Mahler TDI overall score, mean (SD) ${ }^{\dagger \dagger}$} \\
\hline Baseline & $7.7(2.61)^{* * *}$ & $7.7(3.41) * * *$ & $8.4(2.94)^{* * *}$ & $7.3(3.01)^{* * *}$ & $7.7(3.00)^{* *}$ \\
\hline Change from baseline to Week 16 & $0.0(3.16)$ & $2.1(3.40)$ & $-0.3(3.28)$ & $1.8(3.28)$ & $1.0(3.41)$ \\
\hline \multicolumn{6}{|l|}{ mRSS total score, mean (SD) } \\
\hline Baseline & $9.6(9.66)$ & $13.3(9.33)$ & $11.1(8.64)$ & $11.6(10.22)$ & $11.4(9.61)$ \\
\hline Week 16 & $8.8(9.18)$ & $13.6(10.15)$ & $11.2(8.94)$ & $11.3(10.55)$ & $11.2(9.90)$ \\
\hline Change from baseline to Week 16 & $-1.1(3.95)^{* *}$ & $0.3(3.40)$ & $0.1(4.32)$ & $-0.7(3.32)^{* *}$ & $-0.4(3.71)^{* *}$ \\
\hline \multicolumn{6}{|l|}{ HAQ-DI score, mean $(\mathrm{SD})^{\ddagger}$} \\
\hline Baseline & $0.55(0.624)$ & $0.58(0.854)$ & $0.45(0.606)$ & $0.63(0.807)$ & $0.57(0.740)$ \\
\hline Week 16 & $0.61(0.719)$ & $0.53(0.895)$ & $0.51(0.729)$ & $0.61(0.852)$ & $0.57(0.805)$ \\
\hline Change from baseline to Week 16 & $0.06(0.502)$ & $-0.05(0.310)$ & $0.06(0.503)$ & $-0.03(0.367)$ & $0.00(0.419)$ \\
\hline \multicolumn{6}{|l|}{ PtGA score, mean $(\mathrm{SD})^{\text {舫 }}$} \\
\hline Baseline & $35.7(27.13)$ & $29.3(28.16)$ & $28.8(26.67)$ & $34.7(28.24)$ & $32.5(27.61)$ \\
\hline Week 16 & $41.7(25.75)$ & $31.5(30.25)$ & $39.7(29.36)$ & $35.0(27.89)$ & $36.7(28.29)$ \\
\hline Change from baseline to Week 16 & $6.0(22.25)$ & $2.3(19.95)$ & $11.0(19.71)$ & $0.3(21.05)$ & $4.2(21.06)$ \\
\hline
\end{tabular}

$* \mathrm{n}=\mathrm{n}-3 . * * \mathrm{n}=\mathrm{n}-2 . * * * \mathrm{n}=\mathrm{n}-1 .{ }^{\dagger}$ Adjusted for hemoglobin. ${ }^{\dagger \dagger}$ Measured using a scale from +9 to -9 . Negative scores indicate more severe dyspnea. ${ }^{\dagger \dagger \dagger}$ Higher values indicate greater skin thickness. ${ }^{\ddagger}$ Visual analog scale scores for HAQ-DI are provided in Supplementary Table 3 (available online at jrheum.org).

\$ Measured using a visual analog scale $(0-100 \mathrm{~mm})$. Higher values indicate more active or severe disease. MMF: mycophenolate mofetil; FVC: forced vital capacity; TDI: Transition Dyspnea Index; mRSS: modified Rodnan skin score; HAQ-DI: Health Assessment Questionnaire-Disability Index; PtGA: patient's global assessment of disease activity. 
HAQ-DI score showed little change from baseline to Week 16, with results similar across the 2- and 4-week titration groups. Mean PtGA scores showed a slight worsening of disease status at study end, and a larger increase in mean PtGA score was seen at Week 16 in the 2- versus 4-week titration group (Table 3), although the data were highly variable. Similarly, a larger increase in PtGA score was seen in the no-MMF versus MMF subgroup.

\section{DISCUSSION}

Our present findings suggest that pirfenidone has an acceptable tolerability profile in patients with SSc-ILD. The TEAE reported during our study were consistent with those observed in 3 randomized, placebo-controlled phase III trials of pirfenidone in IPF $(n=1247)^{17,18}$ and a longterm safety assessment of pirfenidone in IPF $(n=789)^{29}$. Common side effects included headache and fatigue, which were reported by $44.4 \%$ and $36.5 \%$ of patients, respectively. The high proportion of these events may warrant further investigation into their effect on the tolerability of pirfenidone in SSc-ILD. However, these events were all mild or moderate in severity and none were classified as serious or led to treatment discontinuation.

The known adverse effects of pirfenidone on the GI system, skin, and liver ${ }^{17,18}$ were of interest in SSc-ILD because these organ systems are also affected in patients with $\mathrm{SSc}^{1,24,25}$. Although GI AE were common, this was not unexpected because of the high frequency of such events observed in clinical trials of pirfenidone in patients with IPF, although patients with moderate to severe gastroesophageal reflux disease (UCLA GIT reflux subscale score > 1.0) were excluded from our study. Patient assessment of GI side effects using the UCLA SCTC GIT 2.0 score suggested the GI effects were stable between baseline and Week 16. This tool has previously been shown to be sensitive to changes in GI symptoms in $\mathrm{SSc}^{2,30,31}$. However, because the UCLA SCTC GIT questionnaire only identified AE occurring within 7 days prior to its use at the baseline and final visits, it is possible that the symptoms reported as AE during our study may have resolved in the intervening weeks. More AE may have been identified if the questionnaire had been administered more frequently.

The frequency and type of TEAE reported during the standard 2-week and the longer 4-week titration schedule reflect the favorable tolerability profile of pirfenidone in SSc-ILD. Over the course of our study, severe TEAE, TE $\mathrm{SAE}$, and TEAE leading to discontinuation were more common in patients who had undertaken the 2- rather than the 4-week titration. This was also the case for dose modifications; however, it should be noted that dose adjustments were made at the discretion of the investigator for safety or tolerability reasons; more specific information was not recorded. Overall, these findings suggest that the titration schedule may affect pirfenidone tolerability and it is possible that patients who are susceptible to the AE commonly associated with pirfenidone may benefit from a longer titration period. Indeed, future studies investigating pirfenidone in SSc-ILD should use a 4-week titration schedule.

MMF is increasingly used in SSc-ILD and it is important that any new SSc-ILD therapy can be tolerated in conjunction with this medication. In our study, MMF was received by $63.5 \%$ of patients in addition to pirfenidone, with similar tolerability to pirfenidone alone; this is notable given the known GI toxicity of both treatments ${ }^{17,18,32}$. Further, patients who took pirfenidone and MMF, compared with pirfenidone alone, appeared to experience fewer severe TEAE and discontinuations and had a greater improvement in dyspnea scores (although this may be due to the small size of each subgroup or imbalances in patient characteristics or background disease at baseline). The reason for the lower rate of infections reported in patients receiving MMF versus no MMF remains unclear; however, it is reassuring that MMF did not increase the rate of infections in patients with SSc-ILD. Further research is required to support this finding and provide a rationale.

Given the overlapping pathogenic mechanisms between SSc-ILD and IPF ${ }^{2,5,21}$, it may be possible that pirfenidone would slow the deterioration of lung function in patients with SSc-ILD ${ }^{17,18}$. Although stable results were reported in the exploratory disease outcomes, our study was not designed with sufficient duration to assess efficacy and the study population was not enriched for more advanced disease (which may explain why no patients received concomitant CYC). Future trials should consider enrichment of study populations to include patients with progressive disease to reduce the number of patients needed to detect a treatment effect $^{33,34}$. A further limitation to be considered when reviewing the results from efficacy analyses is that ours was a small-scale exploratory study without a comparator group, and the dosing of MMF was also not uniform.

In our study, pirfenidone showed an acceptable tolerability profile in patients with SSc-ILD. While co-administration of MMF did not appear to affect overall tolerability, a longer dose titration may have a favorable effect on tolerability. Although these results have few immediate clinical implications, the findings from the LOTUSS study are encouraging and permit further investigation of the efficacy and longterm safety of pirfenidone in future clinical trials in patients with SSc-ILD.

\footnotetext{
ACKNOWLEDGMENT

The authors thank all the patients who consented to participate in our exploratory study. The authors thank Dr. Renato Carignola, Clinical Rheumatologist, at the Scleroderma Unit, University of Turin, for his helpful contributions to the Multidisciplinary Interstitial Lung Disease Group discussions. The authors acknowledge David Kardatzke and Chin-Yu Lin of Roche-Genentech, and Hong Tang, formerly of InterMune, for their work on the statistical analyses for the LOTUSS study. Medical writing support was provided by Lauren Donaldson, on behalf of Complete Medical Communications Ltd., funded by F. Hoffmann-La Roche Ltd.
}

Personal non-commercial use only. The Journal of Rheumatology Copyright @ 2016 . All rights reserved. 


\section{ONLINE SUPPLEMENT}

Supplementary data for this article are available online at jrheum.org.

\section{REFERENCES}

1. van den Hoogen F, Khanna D, Fransen J, Johnson SR, Baron M, Tyndall A, et al. 2013 classification criteria for systemic sclerosis: an American College of Rheumatology/European League against Rheumatism collaborative initiative. Arthritis Rheum 2013; 65:2737-47.

2. Solomon JJ, Olson AL, Fischer A, Bull T, Brown KK, Raghu G. Scleroderma lung disease. Eur Respir Rev 2013;22:6-19.

3. Steen VD, Medsger TA. Changes in causes of death in systemic sclerosis, 1972-2002. Ann Rheum Dis 2007;66:940-4.

4. Khanna D, Seibold JR, Wells A, Distler O, Allanore Y, Denton C, et al. Systemic sclerosis-associated interstitial lung disease: lessons from clinical trials, outcome measures, and future study design. Curr Rheumatol Rev 2010;6:138-44.

5. Herzog EL, Mathur A, Tager AM, Feghali-Bostwick C, Schneider F, Varga J. Review: interstitial lung disease associated with systemic sclerosis and idiopathic pulmonary fibrosis: how similar and distinct? Arthritis Rheumatol 2014;66:1967-78.

6. Bouros D, Wells AU, Nicholson AG, Colby TV, Polychronopoulos V, Pantelidis P, et al. Histopathologic subsets of fibrosing alveolitis in patients with systemic sclerosis and their relationship to outcome. Am J Respir Crit Care Med 2002;165:1581-6.

7. Kowal-Bielecka O, Landewé R, Avouac J, Chwiesko S, Miniati I, Czirjak L, et al; EUSTAR Co-Authors. EULAR recommendations for the treatment of systemic sclerosis: a report from the EULAR Scleroderma Trials and Research group (EUSTAR). Ann Rheum Dis 2009;68:620-8.

8. Bussone $\mathrm{G}$, Mouthon L. Interstitial lung disease in systemic sclerosis. Autoimmun Rev 2011;10:248-55.

9. Tashkin DP, Elashoff R, Clements PJ, Goldin J, Roth MD, Furst DE, et al; Scleroderma Lung Study Research Group. Cyclophosphamide versus placebo in scleroderma lung disease. N Engl J Med 2006;354:2655-66.

10. Cappelli S, Guiducci S, Bellando Randone S, Matucci Cerinic M. Immunosuppression for interstitial lung disease in systemic sclerosis. Eur Respir Rev 2013;22:236-43.

11. Schoenfeld SR, Castelino FV. Interstitial lung disease in scleroderma. Rheum Dis Clin North Am 2015;41:237-48.

12. Clements PJ, Tashkin D, Roth M, Khanna D, Furst DE, Tseng CH, et al. The Scleroderma Lung Study II (SLS II) shows that both oral cyclophosphamide (CYC) and mycophenolate mofitil (MMF) are efficacious in treating progressive interstitial lung disease (ILD) in patients with systemic sclerosis (SSc) [abstract]. Arthritis Rheumatol 2015;67 Suppl 10:1401-2.

13. Schaefer CJ, Ruhrmund DW, Pan L, Seiwert SD, Kossen K. Antifibrotic activities of pirfenidone in animal models. Eur Respir Rev 2011;20:85-97

14. Nakazato H, Oku H, Yamane S, Tsuruta Y, Suzuki R. A novel anti-fibrotic agent pirfenidone suppresses tumor necrosis factor-alpha at the translational level. Eur J Pharmacol 2002;446:177-85.

15. Iyer SN, Hyde DM, Giri SN. Anti-inflammatory effect of pirfenidone in the bleomycin-hamster model of lung inflammation. Inflammation 2000;24:477-91.

16. European Medicines Agency. Esbriet: pirfenidone. [Internet. Accessed May 30, 2016.] Available from: www.ema.europa.eu/ema/index.jsp?curl=pages/medicines/ human/medicines/002154/human_med_001417.jsp\&mid= WC0b01ac058001d124

17. King TE Jr, Bradford WZ, Castro-Bernardini S, Fagan EA, Glaspole I, Glassberg MK, et al. A phase 3 trial of pirfenidone in patients with idiopathic pulmonary fibrosis. N Engl J Med 2014; 370:2083-92.
18. Noble PW, Albera C, Bradford WZ, Costabel U, Glassberg MK, Kardatzke D, et al; CAPACITY Study Group. Pirfenidone in patients with idiopathic pulmonary fibrosis (CAPACITY): two randomised trials. Lancet 2011;377:1760-9.

19. Genentech. Esbriet prescribing information. [Internet. Accessed May 30, 2016.] Available from: www.gene.com/download/pdf/esbriet_prescribing.pdf

20. Raghu G, Collard HR, Egan JJ, Martinez FJ, Behr J, Brown KK, et al; ATS/ERS/JRS/ALAT Committee on Idiopathic Pulmonary Fibrosis. An official ATS/ERS/JRS/ALAT statement: idiopathic pulmonary fibrosis: evidence-based guidelines for diagnosis and management. Am J Respir Crit Care Med 2011;183:788-824.

21. King TE Jr, Pardo A, Selman M. Idiopathic pulmonary fibrosis. Lancet 2011;378:1949-61.

22. Albera C, Bradford WZ, Costabel U, Fagan EA, Glaspole I, Glassberg MK, et al. Pirfenidone is efficacious in patients with idiopathic pulmonary fibrosis (IPF) and mild restrictive disease [abstract]. Am J Respir Crit Care Med 2015;191:A1018.

23. Noble PW, Albera C, Bradford WZ, Costabel U, du Bois RM, Fagan EA, et al. Pirfenidone for idiopathic pulmonary fibrosis: analysis of pooled data from three multinational phase 3 trials. Eur Respir J 2016;47:243-53.

24. Rigamonti C, Bogdanos DP, Mytilinaiou MG, Smyk DS, Rigopoulou EI, Burroughs AK. Primary biliary cirrhosis associated with systemic sclerosis: diagnostic and clinical challenges. Int $\mathrm{J}$ Rheumatol 2011;2011:976427.

25. Savarino E, Furnari M, de Bortoli N, Martinucci I, Bodini G, Ghio $\mathrm{M}$, et al. Gastrointestinal involvement in systemic sclerosis. Presse Med 2014;43:e279-91.

26. Preliminary criteria for the classification of systemic sclerosis (scleroderma). Subcommittee for scleroderma criteria of the American Rheumatism Association Diagnostic and Therapeutic Criteria Committee. Arthritis Rheum 1980;23:581-90.

27. Khanna D, Hays RD, Maranian P, Seibold JR, Impens A, Mayes $\mathrm{MD}$, et al. Reliability and validity of the University of California, Los Angeles Scleroderma Clinical Trial Consortium Gastrointestinal Tract Instrument. Arthritis Rheum 2009;61:1257-63.

28. Cancer Therapy Evaluation Program. Common terminology criteria for adverse events, version 3.0 (CTCAE). [Internet. Accessed May 30, 2016.] Available from: ctep.cancer.gov/protocolDevelopment/ electronic_applications/docs/ctcaev3.pdf

29. Valeyre D, Albera C, Bradford WZ, Costabel U, King TE Jr, Leff JA, et al. Comprehensive assessment of the long-term safety of pirfenidone in patients with idiopathic pulmonary fibrosis Respirology 2014;19:740-7.

30. Bae S, Allanore Y, Furst DE, Bodukam V, Coustet B, Morgaceva O, et al. Associations between a scleroderma-specific gastrointestinal instrument and objective tests of upper gastrointestinal involvements in systemic sclerosis. Clin Exp Rheumatol 2013;31 Suppl 76:57-63.

31. Khanna D, Furst DE, Maranian P, Seibold JR, Impens A, Mayes MD, et al. Minimally important differences of the UCLA Scleroderma Clinical Trial Consortium Gastrointestinal Tract Instrument. J Rheumatol 2011;38:1920-4.

32. Behrend M. Adverse gastrointestinal effects of mycophenolate mofetil: aetiology, incidence and management. Drug Saf 2001;24:645-63.

33. Khanna D, Brown KK, Clements PJ, Elashoff R, Furst DE, Goldin $\mathrm{J}$, et al. Systemic sclerosis-associated interstitial lung disease-proposed recommendations for future randomized clinical trials. Clin Exp Rheumatol 2010;28 Suppl 58:S55-62.

34. Khanna D, Nagaraja V, Tseng CH, Abtin F, Suh R, Kim G, et al. Predictors of lung function decline in scleroderma-related interstitial lung disease based on high-resolution computed tomography: implications for cohort enrichment in systemic sclerosis-associated interstitial lung disease trials. Arthritis Res Ther 2015;17:372. 